\title{
Internalização de novos membros em equipes de desenvolvimento de software: uma versão detalhada
}

\section{Title: Onboarding of new members in software development teams: a detailed version}

\author{
Patrícia Cristina Moser e Joelson Isidro da Silva Araújo
}

Centro de Informática (CIn) - Universidade Federal de Pernambuco (UFPE) Programa de Pós-Graduação em Ciência da Computação

Av. Jornalista Aníbal Fernandes, s/n, Cidade Universitária, Recife - PE - Brasil

$\{$ pcm3, jisa\}@cin.ufpe.br

\begin{abstract}
Context: The internalization of new members in software development teams causes changes in organizations and needs to be studied. Objective: To investigate the benefits and limitations of internalization in software development teams. Method: A qualitative study was carried out at a startup where internalization was observed recently. The data were analyzed using qualitative coding techniques and the results were verified and validated with the participants through the verification of members. Results: it is clear that internalization is strongly influenced by the culture of the company studied and the reception and integration of time. Conclusion: The internalization of new members generates greater synergy, which strongly helps without objective of the organizational results.
\end{abstract}

Keywords. Internalization; Organizational culture; Integration; Reception; Software Engineering; Development Teams.

Resumo. Contexto: A internalização de novos membros em equipes de desenvolvimento de software ocasiona mudanças nas organizações e precisa ser estudada. Objetivo: Investigar os benefícios e limitações da internalização em equipes de desenvolvimento de software. Método: Foi realizado um estudo qualitativo em uma startup onde a internalização foi observada recentemente. Os dados foram analisados utilizando técnicas de codificação qualitativa e os resultados foram verificados e validados com os participantes por meio da verificação de membros. Resultados: Percebeu-se que a internalização sofre forte influência da cultura da empresa estudada e do acolhimento e integração do time. Conclusão: A internalização de novos membros gera uma maior sinergia, que ajuda fortemente no objetivo dos resultados organizacionais.

Palavras-Chave Internalização; Cultura Organizacional; Integração; Acolhimento; Engenharia de Software; Times de Desenvolvimento.

\section{Introdução}

Durante várias décadas, a pesquisa sobre gestão de recursos humanos investigou práticas para melhorar o desempenho de pessoas no trabalho [Ollo-Lopez et al., 2010]. Esses 
estudos se concentram em indivíduos - em vez das equipes ou da organização como um todo - e consideram a experiência dos trabalhadores e as práticas de trabalho individuais como um dos principais elementos para aumentar o desempenho do trabalho.

Em contrapartida, as equipes são um fator fundamental no âmbito social e organizacional e vem sendo estudadas desde o final dos anos 1920 [Cannon-Bowers e Bowers, 2011]. Nas últimas décadas, diante do reconhecimento da importância do trabalho em equipe para o sucesso das organizações, esse passou a ser um dos principais temas de trabalhos acadêmicos, focando em diferentes contextos organizacionais, buscando, em sua maioria, compreender como formar equipes de alto desempenho.

Em um estudo mais abrangente, Kozlowski e Ilgen (2006) sintetizaram resultados de pesquisas sobre trabalho em equipe e chegaram à definição de que uma equipe pode ser (a) formada por dois ou mais indivíduos; (b) que interagem socialmente; (c) possuem um ou mais objetivos comuns; (d) executam, em conjunto, tarefas organizacionalmente relevantes; (e) possuem interdependências com relação ao fluxo de trabalho, objetivos e resultados; (f) têm papéis e responsabilidades diferentes; e (g) estão envolvidos por um sistema organizacional abrangente, com fronteiras e ligações com um contexto mais amplo em um ambiente orientado a tarefas. No trabalho de DeOrtenntiis et al. (2013), os autores afirmam que a essência do trabalho em equipe consiste em um conjunto de indivíduos trabalhando de forma coletiva e interdependente, a fim de alcançar objetivos que não poderiam ser alcançados com indivíduos que realizam suas atividades de forma independente. No entanto, as equipes, em geral, são sistemas sociais complexos e requerem interdependência entre seus membros. Para este trabalho, uma equipe pode ser entendida como um conjunto de indivíduos com habilidades que são interdependentes em suas tarefas e que compartilham a responsabilidade com foco em resultados comuns.

Em relação à importância, não há como discutir sobre a relevância do trabalho em equipe no desenvolvimento de software, sendo em equipes ágeis ou tradicionais. No desenvolvimento tradicional, o estudo de Faraj e Sproull (2000) mostrou uma forte relação entre o gerenciamento da experiência e o desempenho da equipe. No desenvolvimento ágil, alguns estudos analisaram o trabalho em equipe usando modelos de desempenho em equipe, como o encontrado em Moe et al. (2010). Sharp e Robinson (2010) descreveram como as equipes de desenvolvimento ágil possibilitam a colaboração, coordenação e comunicação. Outro estudo [Pikkarainen et al., 2008], focado em como os métodos de desenvolvimento ágil melhoram a comunicação, afirmou que as práticas de Scrum e XP (Extreme Programming) melhoram a comunicação formal e informal. Maruping et al. (2009) demonstraram que as práticas XP de propriedade coletiva de códigos e padrões de codificação poderiam levar ao aumento da qualidade técnica dos produtos de software. Uma pesquisa dos fatores de sucesso do desenvolvimento ágil constatou que a capacidade da equipe era um desses fatores [Chow e Cao, 2008]. Todos os autores mencionados apontam para os pontos positivos do trabalho em equipe, mas também existem pontos desfavoráveis que devem ser levados em consideração.

Um problema bastante comum nas equipes de desenvolvimento de software é a rotatividade de membros, conhecida por job rotation. Essa rotatividade pode se dar por conta do desligamento de um indivíduo ou por substituição/rodízio entre as equipes. É possível encontrar trabalhos que buscam entender como a prática do job rotation influencia a motivação e satisfação dos engenheiros de software [Santos, 2015], e também quais os efeitos positivos e negativos para a empresa e o engenheiro com esta rotação 
[Santos et. al, 2016]. Mesmo assim, é possível identificar uma oportunidade de pesquisa que busque compreender os efeitos da inclusão de novos membros nas equipes de software, e entender como se dá a chegada de um novo indivíduo em um time existente. Este fenômeno será chamado, neste trabalho, de "internalização".

Isto posto, este artigo trata-se de uma versão ampliada do trabalho realizado por Moser et al. (2019), cujo objetivo foi investigar quais os benefícios e limitações do processo de internalização de um novo indivíduo em uma equipe de desenvolvimento de software.

No artigo mencionado, foi realizado um estudo qualitativo, utilizando técnicas de codificação, com o objetivo de coletar dados sobre o processo de internalização de novos membros em uma startup pernambucana. Os dados coletados foram analisados e os resultados foram verificados e validados com os participantes através da verificação de membros. Tal verificação é um processo importante de controle de qualidade na pesquisa qualitativa, onde os participantes recebem a oportunidade de revisar suas declarações [Harper e Cole, 2012]. O maior benefício da realização de verificações de membros é que permite ao pesquisador a oportunidade de verificar a precisão e a credibilidade do que foi registrado durante uma entrevista de pesquisa, o que ajuda a melhorar a validade do estudo [Cohen e Crabtree, 2006].

Por ser uma versão estendida, os aspectos metodológicos são mais bem explorados, descrevendo com mais detalhes o processo da análise qualitativa realizado. Outrossim, este artigo traz uma versão detalhada do estudo citado, sendo relevante ao apresentar, de forma detalhada, o fenômeno da internalização de um novo indivíduo em equipes de desenvolvimento de software, uma vez que fornece evidências empíricas sobre os benefícios e limitações sentidas não só pelos integrantes do time, como também pelos novos membros. Espera-se que os resultados desta pesquisa possam contribuir para a compreensão do fenômeno estudado, como forma de incrementar os pontos fortes dos colaboradores a partir de uma perspectiva mais positiva nas relações de trabalho.

O artigo está organizado da seguinte forma: a seção 2 apresenta o referencial teórico desta pesquisa; a seção 3 apresenta os trabalhos relacionados; a seção 4 mostra o método utilizado neste estudo; os resultados obtidos são apresentados na seção 5; as discussões são apresentadas na seção 6; a seção 7 apresenta as ameaças à validade e, finalmente, as conclusões são apresentadas na seção 8.

\section{Referencial Teórico}

Projetos de software são geralmente desenvolvidos em equipes e estas nem sempre são estáveis. Segundo Farshchi et al. (2012), apesar de ampliar a disponibilidade do time, adicionar novos membros em um projeto em andamento pode causar impactos negativos na produtividade devido ao tempo de assimilação, treinamento e comunicação entre os integrantes.

Nesta seção, serão abordados os conceitos mais importantes relacionados à temática explorada, a saber: fatores humanos em engenharia de software, cultura organizacional, integração/acolhimento e a internalização. Por fim, os trabalhos relacionados serão apresentados. 


\subsection{Fatores Humanos em Engenharia de Software}

O desenvolvimento de software é uma atividade intelectual que depende essencialmente de pessoas, que geralmente formam equipes e trabalham juntas para entregar os softwares ou serviços contratados [Miranda, 2011]. É impossível excluir os fatores humanos durante o desenvolvimento de software, porque o software é desenvolvido por pessoas e para elas.

A natureza intangível do software tornou um produto difícil de ser criado com sucesso, e um exame minucioso das razões para as principais falhas no sistema de software mostra que várias delas estão relacionadas a problemas humanos. Se por um lado os profissionais de software, imersos no aspecto tecnológico do produto, aprendem questões relacionadas às falhas tecnológicas e encontram soluções para evitá-las no futuro, por outro lado têm dificuldades em aprender lições relacionadas aos aspectos humanos da engenharia de software. Tais aspectos continuam a ser uma área de pesquisa negligenciada, e as possíveis razões para essa lacuna são: as relações complexas entre a psicologia humana e os processos de desenvolvimento de software, a falta de consciência do impacto dos fatores humanos na engenharia de software e, possivelmente, a falta de confiança nos estudos empíricos sobre os fatores humanos [Capretz et al., 2017].

Apesar desse panorama, é importante destacar os esforços que estão sendo feitos para diminuir essa lacuna. A academia, por exemplo, apresenta diversos fóruns nacionais e internacionais que buscam analisar fatores humanos e como eles podem impactar no desenvolvimento de software. São eles: Workshop sobre Aspectos Sociais, Humanos e Econômicos de Software (WASHES), Simpósio Brasileiro de Sistemas de Informação (SBSI), Simpósio Brasileiro de Sistemas Colaborativos (SBSC), Simpósio Brasileiro sobre Fatores Humanos em Sistemas Computacionais (IHC), Revista Brasileira de Sistemas de Informação (iSys), International Workshop on Cooperative and Human Aspects of Software Engineering (CHASE), e Computers in Human Behavior Journal.

Silva (2017) realizou um mapeamento sistemático da literatura para investigar a influência de fatores humanos e culturais em projetos de desenvolvimento de software. Um dos resultados indicou que os aspectos humanos fazem parte dos 14 fatores críticos de sucesso em projetos ágeis. Além disso, o estudo consolida os conceitos existentes sobre os fatores humanos no desenvolvimento, execução e sucesso dos softwares ágeis.

Os aspectos humanos são considerados de grande relevância para a construção de um produto. Conforme afirmam Moe e Dingsøyr (2008), há complexidade no desenvolvimento de um software, especialmente, pela interferência das questões humanas no resultado final, uma vez que a efetividade da construção de software depende do desempenho da equipe, e esta sofre influência de diversos fatores, tais como: relações interpessoais, motivação, satisfação, habilidades, competências, comunicação e trabalho em equipe.

Pesquisas sobre essa temática revelam alguns fatores humanos relacionados à engenharia de software, tais como: personalidade, motivação, trabalho de equipe e comunicação. No aspecto personalidade, Capretz e Ahmed (2010) mapearam habilidades sociais e traços psicológicos que interferem no ciclo de vida do software. Esses autores acreditam que há traços de personalidade mais adequados para o êxito de um projeto. Mourmant e Gallivan (2007) acreditam que o perfil dos profissionais de tecnologia da informação (TI) tem impacto direto na satisfação com o trabalho e nas mudanças de 
emprego, isso porque os perfis individuais são decisivos na escolha por processos de trabalho, o que garante, inclusive, a rotatividade de funções dentro de um ambiente profissional.

O aspecto motivação tem sido um objeto recorrente de estudo com o objetivo de buscar um desempenho maior e mais saudável nas equipes de desenvolvimento de software [Viana et al., 2012]. Oliveira e França (2019) investigaram como as práticas ágeis estão relacionadas à motivação dos indivíduos e concluem que seguir o gerenciamento de requisitos ágil e entregar funcionalidades antes do prazo, estão entre as práticas mais impactantes na motivação. A motivação dos membros do time também tende a aumentar quando as pessoas se sentem apreciadas, recompensadas e com uma atmosfera positiva de competição, melhorando desempenho da equipe [Hermando, Kaburuan e Legowo, 2018]. Outros fatores que motivam são a autonomia, a variedade, a importância, o feedback e a capacidade de concluir uma tarefa inteira [Tessem e Maurer, 2007].

Para Oliveira (2011), a nova gestão de recursos humanos é decorrente da valorização dos fatores psicológicos e sociais envolvidos na produtividade, trazendo novo sentido ao gerir pessoas. Nesse sentido, a ênfase do fator humano nas organizações contribui para o desenvolvimento de novas estratégias para fazer com que os trabalhadores sejam vistos como colaboradores e não mais como meros recursos [Quinn, 2003; Merli, 2008].

Diante dessa nova realidade, as empresas precisam estar atentas e, mais do que isso, precisam estar preparadas para desenvolver as habilidades dos seus colaboradores, tornando-os talentosos, pois estes devem saber utilizar, consciente e corretamente, todas as possibilidades que o mundo moderno traz, como opção para tornar o seu desempenho mais dinâmico.

\subsection{Cultura Organizacional}

Cultura Organizacional pode ser definida como um padrão de pressupostos que um determinado grupo criou, descobriu ou desenvolveu durante seu processo de aprendizagem para lidar com seus problemas de adaptação externa e integração interna, e que funcionou bem o suficiente para ser considerado válido e, portanto, para ser ensinado a novos membros como a maneira correta de perceber, pensar e sentir em relação a esses problemas [Schein, 1984].

Segundo Berger e Luckman (1984), a cultura é socialmente construída e é o produto de escolhas explícitas e implícitas que são impostas ou renegociadas e expressas através da linguagem e da ação. Além disso, a cultura tem sido vista como um elemento influenciador que afeta a moral do empregado, sua motivação e disposição; nível de produtividade e eficácia; a qualidade do trabalho; inovação e criatividade e a atitude dos funcionários no local de trabalho [Campbell et al., 1999]. MacGregor et al. (2005) afirmam que a cultura consiste em modos padronizados de pensar, sentir e reagir, adquiridos e transmitidos principalmente por símbolos, constituindo a conquista distinta de grupos humanos, incluindo suas personificações em artefatos. A essência da cultura consiste em ideias tradicionais e principalmente em seus valores atraídos. Ainda, Cameron e Quinn (2011) argumentam que a cultura é uma chave para a vantagem competitiva. 
As diferenças culturais afetam as suposições das pessoas, geradas durante as interações, tornando-se dúbio o entendimento de suas condutas, suas expectativas sobre as práticas de liderança e suas habilidades de trabalho [Moe and Smite, 2007]. Afetam, também, o entendimento das ações realizadas pelos participantes e das necessidades para o desempenho de uma tarefa. No desenvolvimento de software, por exemplo, as diferenças de culturas organizacionais podem causar alguns problemas como os diversos entendimentos do que significa realizar testes de unidade (Mockus e Herbsleb, 2001), a dificuldade de chegar a um consenso de qual seria o uso do sistema (Damian e Zowghi, 2003) e a visão diferente do que é qualidade (Kobitzsch et al., 2001).

Para Robbins (2005), a cultura organizacional está vinculada a uma percepção em comum dos integrantes de uma instituição e que esta noção fica demonstrada quando se define cultura como um sistema compartilhado de valores. $O$ autor menciona que existem sete características que, juntas, captam a essência da cultura: inovação; aceitação de riscos; atenção aos detalhes; orientação para resultados; pessoas e equipes; agressividade e estabilidade. Tais características evidenciam um quadro complexo de diagnóstico da cultura organizacional.

Neste sentido, a cultura organizacional possui propensão a ser específica em cada instituição, sendo composta por níveis objetivos e subjetivos e, embora existam várias definições e empregos do conceito de cultura em nível organizacional, um tópico integrador é o costume, vinculado à tradição e crenças compartilhadas sobre a vida organizacional. Por ser um elemento poderoso do comportamento individual e em grupo, a cultura organizacional tende a afetar muitos aspectos da vida da organização, seja por meio da forma como as pessoas se relacionam, realizam suas atividades, e se vestem; ou pelos tipos de decisão tomados na empresa, os procedimentos realizados e as estratégias utilizadas (BOWDITCH; BUONO, 2006).

\subsection{Integração e Acolhimento}

Nos modelos de gestão atuais um dos maiores focos de preocupação é com a gestão do capital humano, ou seja, a sensação de bem-estar e motivação dos colaboradores. Esta mudança de paradigma é explicada pelo fato de o capital humano ser considerado como o motor principal para o sucesso organizacional, ainda que não seja fácil quantificar qual o valor dessa contribuição para a concretização dos resultados [Cunha, 2014].

O processo de integração e de acolhimento estão inseridos em um conceito maior, que é a socialização organizacional. Desde 1980, Louis a define como o processo pelo qual os novos membros de uma organização iniciam o contato com os valores organizacionais, visualizam os comportamentos desejados e passam a ter conhecimentos essenciais para assumirem o seu papel na organização. Esse primeiro contato abrange, além da identificação e do conhecimento dos valores, a transparência do papel organizacional e, por fim, promove a edificação da rede de relações. Portanto pode-se afirmar que a socialização é caracterizada como um processo primário de adaptação mútua entre indivíduo-organização-indivíduo, desempenhando função essencial para as organizações, pois proporciona a comunicação da cultura organizacional, fornece conforto e acolhimento no primeiro contato com a nova realidade e oportuniza aos novos colaboradores o enquadramento para fazerem frente aos acontecimentos em seu ambiente de trabalho [Bauer et al., 2007]. 
A formação de acolhimento e integração de novos trabalhadores pode ser um dos primeiros passos para criar laços de identidade entre o trabalhador e a organização. Eles mais facilmente se adequam à cultura organizacional, aos padrões de comportamento considerados aceitáveis pela mesma, aos colegas de trabalho e à liderança.

Estudos realizados por Silva e Fossa (2015) afirmam que os procedimentos relativos à socialização vêm sendo aprimorados ao longo do tempo e contam com total apoio dos gestores e dos diretores, denotando proatividade da organização em termos de proporcionar uma primeira boa impressão a seus novos integrantes. Situação que a organização considera fundamental, facilitando o processo de transição e auxiliando na redução da ansiedade e insegurança inicial que todo e qualquer processo de mudança causa nos indivíduos.

Ainda, a partir do momento em que os sujeitos se identificam com a organização da qual começam a fazer parte, poderão servir de instrumento de desenvolvimento, auxiliando a modificá-la do estado atual para um melhor, deixando, assim, as pessoas alcançarem um papel mais dinâmico e eficaz. É necessário que o colaborador seja trabalhado não apenas na sua entrada na organização, mas também durante toda a sua estada nela [Silva e Fossa, 2015].

\subsection{Internalização}

O termo internalização não é um conceito novo e tem diferentes significados dependendo da área em que é utilizado. Na sociologia e outras ciências sociais, vertentes mais próximas da prática estudada, internalização significa a aceitação de um indivíduo para um conjunto de normas e valores estabelecidos por outros através da socialização.

Ainda em 1971, John F. Scott descreveu a internalização através de uma metáfora, na qual algo (ex. uma ideia, conceito, ação) se move de fora da mente ou personalidade para um local dentro dela. Este processo de internalização começa com o aprendizado sobre as normas. Em seguida, o indivíduo passa pelo processo de entender por que elas são importantes e por que fazem sentido até, finalmente, aceitar as normas com seu próprio ponto de vista.

Tyler (1997) afirma que o processo de internalização também leva a sentimentos de obrigação moral em respeito ao bem-estar do grupo e vai além da simples troca de favores, levando a ações proativas em prol do grupo e seus membros.

Neste artigo, o conceito é avaliado sob a perspectiva da internalização de pessoas em grupos. Ou seja, quais os impactos do processo da entrada de novos integrantes em equipes de projetos de software. Impactos para o indivíduo, para o grupo e para o projeto.

\section{Trabalhos Relacionados}

A literatura apresenta várias definições para descrever a prática da internalização em equipes de desenvolvimento de software. Nesta seção, serão apresentados alguns estudos que abordam o fenômeno.

No trabalho de Santos et al., (2016), os autores investigaram os efeitos da rotação de tarefas, ou seja, do job rotation, em uma organização de software que utiliza esta prática. $\mathrm{O}$ trabalho focou nas rotações projeto a projeto, em que indivíduos são movidos durante o desenvolvimento de um projeto de software, para trabalhar em outro projeto, na mesma ou em diferentes funções. Os resultados mostram que os efeitos da rotação de 
tarefas no ambiente de trabalho e nos indivíduos eram complexos e inter-relacionados. Os ganhos duradouros obtidos com mais variedade no trabalho e a oportunidade de aprender criaram um efeito adverso no desempenho. Ao mesmo tempo em que um aumento na variedade de trabalho foi considerado positivo, a rotação de trabalho também afetou negativamente a percepção de realização de um trabalho bem definido. Dessa forma, a rotação de tarefas é vista como uma importante prática organizacional que produz resultados positivos. No entanto, os gerentes devem estar cientes dos possíveis efeitos negativos e implantar táticas para equilibrá-los. Importante destacar que o estudo de Santos et al. (2016) forneceu evidências empíricas sobre os impactos da rotação de tarefas no trabalho de engenheiros de software e deixou a proposição de uma teoria de job rotation em engenharia de software.

Em outro estudo, Santos et al. (2016) realizaram uma revisão sistemática da literatura cujo objetivo foi identificar e discutir evidências sobre o job rotation, a fim de entender o uso, os benefícios e as limitações dessa prática nas organizações de software. Os estudos abordaram os tipos de rotações job-to-job (J2J) e project-to-project (P2P) definidos na literatura [Wood, R. 1999] e revelaram que, nas organizações de software, a rotação de tarefas é usada para aprimorar a comunicação, o entendimento organizacional, a troca de conhecimentos e a variedade de tarefas. No entanto, a prática tem algumas limitações, exigindo tempo e, às vezes, planejamento complexo. Eles também revelaram que as rotações $\mathrm{J} 2 \mathrm{~J}$ e $\mathrm{P} 2 \mathrm{P}$ atendem a diferentes necessidades organizacionais e individuais, com resultados distintos e potencialmente conflitantes. Os resultados fornecem achados relevantes para orientar futuras pesquisas e também para beneficiar a prática industrial.

Faegri (2009) relatou experiências de um teste de job rotation entre desenvolvedores no suporte ao cliente em uma organização norueguesa de software. Segundo o autor, as tentativas de construir um conhecimento geral por meio da rotação de tarefas devem ser feitas levando em consideração o desejo inerente das pessoas de concluir suas tarefas com eficiência. Embora alguns benefícios possam aparecer rapidamente (como um entendimento mais claro dos requisitos dos clientes ou a importância da manutenção, por exemplo), apreciações mais profundas das oportunidades de alinhamento tecnológico e produtos futuros podem levar mais tempo. Assim, a gerência deve estar disposta a aceitar o custo da construção do conhecimento geral. As diferenças individuais podem justificar esquemas baseados na participação voluntária, mas isso deve ser ponderado contra o desafio potencial de ter que ajustar o status da rotação do trabalho.

Muitas organizações de software enfrentam ambientes competitivos e turbulentos, aumentando a importância de a empresa poder se beneficiar das habilidades e competências dos seus funcionários [Grant, 1996; Nonaka e Takeuchi, 1995]. Ao utilizar seu acesso à diversidade cognitiva entre indivíduos especializados, a organização pode melhorar seu potencial de aprendizado e inovação. Para grupos e organização, um nível de sobreposição ou redundância no conhecimento é fundamental para uma colaboração eficaz e ação coordenada [Hoopes e Postrel, 1999], e a prática de job rotation é uma abordagem amplamente conhecida. Dentro desse contexto, Fægri et al. (2010) afirmam que a falta de redundância de conhecimento é um fator limitante para colaboração, flexibilidade e coordenação nas equipes e na organização. Dessa forma, os autores investigaram os benefícios e desafios com a melhoria da redundância de conhecimento entre os desenvolvedores que estavam inseridos em atividades de job rotation. 
O estudo realizado por Qureshi e Fang (2011) aborda a importância de motivar, envolver e reter novos desenvolvedores de software livre (open source software - OSS), a fim de promover um número sustentável de desenvolvedores em um projeto. Para os autores, o sucesso dos projetos OSS depende muito da participação voluntária de um grande número de desenvolvedores. Para permanecer sustentável, é vital que uma comunidade de projetos OSS mantenha uma massa crítica de desenvolvedores principais. No entanto, apenas um pequeno número de participantes pode se socializar com êxito no grupo principal de desenvolvedores. Dessa forma, é importante entender como os participantes se socializam e se tornam parte do núcleo da comunidade OSS, e como eles se relacionam com a progressão de status.

Dentro do cenário de código aberto, Steinmacher et. al. (2014) apresentam um modelo, denominado developer joining model, que visa representar os estágios comuns aos desenvolvedores (ao decidirem ingressar em um projeto) e as forças que influenciam os recém-chegados a serem atraídos ou afastados de um projeto de código aberto. Embora a motivação persista como uma força contínua, vários fatores impeditivos e forças de retenção influenciam a integração, a contribuição e a permanência dos membros. Para os autores, a "motivação" e "atratividade" são os fatores que levam o novo integrante a contribuir com o projeto. As forças de motivação representam motivos internos (por exemplo, aprendizado, auto marketing, reconhecimento) e externos (por exemplo, bolsa de estudos, atribuição de curso, necessidade de recursos) que levam um desenvolvedor a ingressar (e continuar contribuindo) em um projeto. Essas forças podem mudar e/ou evoluir durante o processo de desenvolvimento, e a falta da motivação leva a desistências. Já as forças de "atratividade" representam as características e ações que o projeto apresenta para atrair novos usuários e desenvolvedores. Essas forças podem incluir o tipo de licença, a visibilidade do projeto, a idade do projeto, o número de desenvolvedores etc. A "atratividade" e a "motivação" trabalham juntas para incentivar desenvolvedores de fora para os projetos.

Ainda, Steinmacher et al., (2014) afirmam que, durante a integração, a motivação continua conduzindo o desenvolvedor em direção ao projeto. No entanto, algumas forças opostas, os chamados "fatores impeditivos", podem dificultar o processo de adesão dos desenvolvedores. Essas forças compreendem fatores técnicos e não técnicos, incluindo curva de aprendizado, falta de apoio da comunidade, dificuldades em encontrar como começar etc. Por fim, o modelo mostra que as forças de retenção podem ajudar a incentivar os recém-chegados a permanecer dispostos a contribuir com o projeto. $\mathrm{O}$ modelo apresentado é útil para que as comunidades de projetos open source possam planejar investimentos para melhor apoiar a adesão de novos membros. Em outro trabalho, Fagerholm e Guinea (2014) investigaram os impactos da internalização de membros em equipes de software globais. Essa preocupação em particular é especialmente relevante para equipes virtuais em um contexto de código aberto, onde os desenvolvedores ingressam e saem rapidamente, e a integração é necessária continuamente. Os autores afirmam que o suporte dado aos desenvolvedores, como por exemplo a mentoria, influencia positivamente no processo de integração.

Como pode ser observado até o momento, os trabalhos correlatos apresentados mencionam práticas de job rotation, e como a rotação de tarefas e de pessoas pode influenciar no time de desenvolvimento. Também apresentam como a socialização de novos integrantes pode reter (ou não) novos desenvolvedores, tanto em times globais como em equipes de código aberto. $\mathrm{O}$ atual estudo diferencia-se dos demais trabalhos por 
investigar benefícios e limitações do processo de internalização em uma startup, sob a perspectiva dos desenvolvedores recém-chegados e também dos experientes. Entender esse fenômeno é fundamental, tanto para estabelecer funcionários novos como para aproveitar ao máximo funcionários experientes. A Tabela 1 traz a comparação dos trabalhos relacionados entre si e com o presente estudo.

Tabela 1: Comparação dos Trabalhos Relacionados

\begin{tabular}{|c|c|c|c|c|}
\hline Trabalhos & $\begin{array}{l}\text { Perspectiva da } \\
\text { Internalização }\end{array}$ & $\begin{array}{c}\text { Coleta de } \\
\text { dados }\end{array}$ & Amostra & Achados \\
\hline $\begin{array}{l}\text { Santos et al. } \\
\text { (2016) - A }\end{array}$ & Job rotation $\mathrm{P} 2 \mathrm{P}$ & $\begin{array}{l}\text {-Entrevistas } \\
\text {-Análise de } \\
\text { documentos } \\
\text {-Questionários }\end{array}$ & $\begin{array}{l}\text { Uma } \\
\text { organização } \\
\text { de software }\end{array}$ & $\begin{array}{l}\text { A rotação de tarefas é uma importante prática } \\
\text { organizacional com resultados positivos. No } \\
\text { entanto, deve-se avaliar os possíveis efeitos } \\
\text { negativos e implantar táticas para equilibrá- } \\
\text { los. }\end{array}$ \\
\hline $\begin{array}{l}\text { Santos et al. } \\
(2016)-\text { B }\end{array}$ & $\begin{array}{l}\text { Job rotation } \mathrm{J} 2 \mathrm{~J} \\
\text { e } \mathrm{P} 2 \mathrm{P}\end{array}$ & $\begin{array}{l}\text { Revisão } \\
\text { sistemática da } \\
\text { literatura }\end{array}$ & $\begin{array}{l}\text { Estudos } \\
\text { primários }\end{array}$ & $\begin{array}{l}\text { A rotação de tarefas é usada para aprimorar a } \\
\text { comunicação, o entendimento organizacional, } \\
\text { a troca de conhecimentos e a variedade de } \\
\text { tarefas. Porém, a prática tem algumas } \\
\text { limitações, exigindo tempo e, às vezes, } \\
\text { planejamento complexo. }\end{array}$ \\
\hline $\begin{array}{l}\text { Faegri } \\
(2009)\end{array}$ & $\begin{array}{l}\text { Job rotation } \\
\text { entre } \\
\text { desenvolvedores }\end{array}$ & $\begin{array}{l}\text { Relato de } \\
\text { experiência }\end{array}$ & $\begin{array}{l}\text { Uma } \\
\text { organização } \\
\text { de software } \\
\text { norueguesa }\end{array}$ & $\begin{array}{l}\text { As tentativas de construir um conhecimento } \\
\text { geral por meio da rotação de tarefas devem ser } \\
\text { feitas levando em consideração o desejo } \\
\text { inerente das pessoas de concluir suas tarefas } \\
\text { com eficiência. }\end{array}$ \\
\hline $\begin{array}{l}\text { Fægri et al. } \\
(2010)\end{array}$ & $\begin{array}{l}\text { Job rotation } \\
\text { entre } \\
\text { desenvolvedores }\end{array}$ & $\begin{array}{l}\text { - Entrevistas; } \\
\text { - Notas de } \\
\text { reuniões; } \\
\text { - Registros de } \\
\text { trabalho }\end{array}$ & $\begin{array}{l}\text { Uma } \\
\text { organização } \\
\text { de software }\end{array}$ & $\begin{array}{l}\text { A rotação de tarefas pode contribuir para } \\
\text { melhorar a redundância de conhecimento. No } \\
\text { entanto, a redundância de conhecimento } \\
\text { incorre em um custo coletivo que deve ser } \\
\text { amortizado e legitimado pela organização. }\end{array}$ \\
\hline $\begin{array}{l}\text { Qureshi e } \\
\text { Fang (2011) }\end{array}$ & $\begin{array}{l}\text { Retenção de } \\
\text { novos } \\
\text { desenvolvedores } \\
\text { de software livre }\end{array}$ & $\begin{array}{l}\text { Estudo de } \\
\text { campo em } \\
\text { base de dados } \\
\text { open source }\end{array}$ & $\begin{array}{l}\text { Participante } \\
\text { s de projetos } \\
\text { de OSS }\end{array}$ & $\begin{array}{l}\text { O sucesso dos projetos OSS depende muito da } \\
\text { participação voluntária de um grande número } \\
\text { de desenvolvedores, entretanto, apenas um } \\
\text { pequeno número de participantes pode se } \\
\text { socializar com êxito no grupo principal de } \\
\text { desenvolvedores. }\end{array}$ \\
\hline $\begin{array}{l}\text { Steinmacher } \\
\text { et. al. (2014) }\end{array}$ & $\begin{array}{l}\text { Modelo } \\
\text { Developer } \\
\text { Joining Model }\end{array}$ & - & $\begin{array}{l}\text { Participante } \\
\text { s de projetos } \\
\text { de OSS }\end{array}$ & $\begin{array}{l}\text { Elaboração de um modelo que visa representar } \\
\text { os estágios comuns aos desenvolvedores e as } \\
\text { forças que influenciam os recém-chegados a } \\
\text { serem atraídos ou afastados de um projeto de } \\
\text { código aberto. A motivação persiste como } \\
\text { uma força contínua, mas vários fatores } \\
\text { impeditivos e forças de retenção influenciam a } \\
\text { integração, a contribuição e a permanência dos } \\
\text { membros. }\end{array}$ \\
\hline $\begin{array}{l}\text { Fagerholm e } \\
\text { Guinea } \\
(2014)\end{array}$ & $\begin{array}{l}\text { Internalização } \\
\text { de membros em } \\
\text { equipes de } \\
\text { software globais }\end{array}$ & Estudo de caso & $\begin{array}{l}\text { Participante } \\
\text { s de projetos } \\
\text { de OSS }\end{array}$ & $\begin{array}{l}\text { O suporte dado aos desenvolvedores, como } \\
\text { por exemplo a mentoria, influencia } \\
\text { positivamente no processo de integração. }\end{array}$ \\
\hline Estudo atual & $\begin{array}{l}\text { Internalização } \\
\text { em uma startup, } \\
\text { sob a } \\
\text { perspectiva dos } \\
\text { desenvolvedores } \\
\text { recém-chegados }\end{array}$ & Entrevistas & $\begin{array}{l}\text { Uma startup } \\
\text { que } \\
\text { desenvolve } \\
\text { software }\end{array}$ & $\begin{array}{l}\text { A internalização de novos membros, se feita } \\
\text { de forma a garantir uma maior homogeneidade } \\
\text { do grupo, gera uma maior sinergia, que ajuda } \\
\text { fortemente no objetivo dos resultados } \\
\text { organizacionais. Porém, é necessário ficar } \\
\text { atento a este processo para não criar um grupo }\end{array}$ \\
\hline
\end{tabular}




\begin{tabular}{|l|l|l|l|}
\hline $\begin{array}{l}\text { e dos } \\
\text { experientes }\end{array}$ & $\begin{array}{l}\text { fechado que dificulte a aceitação de novos } \\
\text { membros, já que o processo de mudança } \\
\text { sempre vai ocorrer. }\end{array}$ \\
\hline
\end{tabular}

\section{Método}

Esta pesquisa busca entender o processo de internalização de novos membros em equipes de desenvolvimento de software e quais os benefícios e limitações desse fenômeno. Foi realizada uma pesquisa qualitativa que, de acordo com Merriam (2009), ao invés de determinar a causa e efeito de alguma variável, ou de prever ou descrever a distribuição de algum atributo entre uma população, está interessada em descobrir o significado de um fenômeno para os envolvidos e entender como as pessoas interpretam suas experiências e o significado que atribuem a elas.

\subsection{Questão de Pesquisa}

Conforme Gil (2010), toda pesquisa se inicia com algum tipo de problema, ou indagação e o mesmo deve ser formulado como pergunta. Para compreender o fenômeno estudado, foi formulada a seguinte questão de pesquisa, a qual este estudo visa responder:

QP: Quais os benefícios e limitações da internalização de membros em equipes de desenvolvimento de software?

A resposta para esta questão de pesquisa é apresentada na Seção 5.

\subsection{As Fases da Pesquisa}

Durante a realização de uma pesquisa qualitativa o pesquisador se envolve em várias fases. Inicialmente foi realizada uma busca na literatura por estudos que pudessem embasar o referencial teórico deste trabalho. A busca foi realizada de forma ad hoc.

Em paralelo ao estudo inicial, foi elaborado um roteiro de entrevistas para a coleta de dados, sendo considerados a vivência do pesquisador, a literatura sobre o tema em estudo e as informações obtidas com a realização de um pré-teste.

Para Triviños (1987), Manzini (1991) e Rea (2000) o pré-teste, ou estudo piloto, também permite verificar a estrutura e a clareza do roteiro, por meio de uma entrevista preliminar. Após um pré-teste realizado dentro da equipe de pesquisadores responsáveis pelo estudo inicial, foi possível identificar e eliminar possíveis problemas com a estruturação do roteiro, o que resultou em alterações que proporcionaram o aprimoramento do instrumento em relação à ordem das questões e ao vocabulário utilizado.

Com o roteiro ajustado, partiu-se para campo, a fim de realizar a coleta de dados. Por fim, procedeu-se a análise dos resultados e redação deste trabalho.

\subsection{Descrição da Empresa e dos Participantes}

A empresa selecionada é uma startup pernambucana de tecnologia, fundada em 2012, especializada em desenvolvimento de softwares com foco no mercado de comunicação e marketing. Na época da coleta de dados, a startup contava com 24 funcionários, sendo 7 da área de desenvolvimento. 
Pela própria característica da startup, que mantém um crescimento contínuo da equipe de desenvolvimento, o fenômeno da internalização é percebido com frequência, uma vez que novos integrantes são inseridos no time, regularmente. Nesse ponto vale ressaltar que o evento pesquisado é em relação à internalização, ou seja, é referente à chegada de novos integrantes em uma equipe já existente; e não à rotatividade dos colaboradores dentro da equipe. O tempo de empresa entre os entrevistados variou de 01 mês a 18 meses. A Tabela 2 apresenta o perfil dos participantes.

Da formação inicial da equipe, apenas o Product Owner (PO) ainda está no time. Todos os outros participantes foram substituídos. Na entrevista com o PO foi observada uma forte questão cultural no processo seletivo, onde os valores de colaboração e de espírito de equipe são fundamentais para que o participante permaneça na equipe.

Tabela 2: Perfil dos participantes

\begin{tabular}{|l|l|l|}
\hline ID & \multicolumn{1}{|c|}{ FUNÇÃo } & TEMPO DE STARTUP \\
\hline P1 & PO (Product Owner) & 18 meses \\
\hline P2 & Designer & 10 meses \\
\hline P3 & Desenvolvedor front-end & 3 meses \\
\hline P4 & Desenvolvedor front-end & 12 meses \\
\hline P5 & Desenvolvedor back-end & 14 meses \\
\hline P6 & Desenvolvedor back-end & 2 meses \\
\hline P7 & Analista devops & 1 mês \\
\hline
\end{tabular}

\subsection{Elaboração do Instrumento}

De acordo com Merriam (2009), recomenda-se o uso de múltiplos métodos para a coleta de dados, entre eles as entrevistas, análise de documentos, questionários e observações. Porém, na ausência dos outros métodos, todos os dados foram coletados através de entrevistas, o método utilizado neste estudo.

Foram realizadas entrevistas semiestruturadas com um grupo de desenvolvedores de software. De acordo com Merriam (2009), a maior parte de uma entrevista semiestruturada é guiada por uma lista de perguntas ou questões a serem exploradas. Este formato permite ao pesquisador responder à situação em questão, à visão de mundo emergente do entrevistado e a novas ideias sobre o tema.

O roteiro de entrevistas seguiu as recomendações propostas por Merriam (2009), onde as perguntas estão no centro das entrevistas e para coletar dados significativos, o pesquisador deve fazer boas perguntas. As questões mais abertas são as melhores de serem utilizadas. Além disso, ter menos perguntas, porém mais abertas, faz com que o pesquisador possa ser flexível no uso do roteiro, permitindo que o pesquisador ouça o que seu entrevistado tem para compartilhar. O roteiro de entrevista para este estudo encontrase disponível em https://bit.ly/2TRyxnz e também pode ser visualizado no Apêndice A.

\subsection{Iniciando a Pesquisa de Campo}

Inicialmente, foi escolhida a empresa para a pesquisa de campo. Essa escolha foi motivada por dois fatores: 1 . o fenômeno da internalização ter ocorrido recentemente e 2 . pelos pesquisadores terem acesso total a todos os indivíduos necessários para a investigação. 


\subsubsection{Seleção dos Participantes}

Como optou-se pela escolha de uma startup em tecnologia, todos os colaboradores que fazem parte da equipe de desenvolvimento foram entrevistados. Isso inclui o gerente de projeto e os demais desenvolvedores. Como o ambiente de pesquisa foi uma startup em crescente desenvolvimento, a prática da internalização foi verificada em vários momentos desde a formação inicial da equipe.

\subsubsection{Entrevistas}

Todas as 7 entrevistas foram realizadas por um entrevistador e apoiadas por um segundo entrevistador, que fazia notas de campo como forma de auxiliar na análise dos dados. Todas os entrevistados autorizaram a gravação das entrevistas, as quais duraram, em média, cerca de 20 minutos, com exceção da entrevista com o PO (Product Owner), que levou 36 minutos. Foram produzidos 150 minutos de áudio e 62 páginas de transcrições. Todas as entrevistas ocorreram nas instalações da startup onde o fenômeno foi observado.

\subsection{Análise dos Dados}

O objetivo da análise qualitativa é consolidar, reduzir e interpretar dados obtidos de várias fontes, e dar sentido a eles [Merriam, 2009]. Envolve rotular e codificar todos os dados, a fim de identificar semelhanças e diferenças para descrever o fenômeno em estudo. Neste estudo, a análise de dados foi realizada em paralelo com a coleta de dados, em etapas incrementais e iterativas, seguindo as recomendações de Merriam (2009).

Os códigos começam a fazer sentido a partir de notas, comentários e observações do pesquisador nas margens das transcrições, e são potencialmente relevantes para o estudo. Esse processo de fazer anotações ao lado de palavras-chave que parecem relevantes para responder as perguntas de pesquisa, é chamado de codificação [Merriam, 2009]. A codificação aberta é feita quando a análise é a mais ampla possível, de forma a indicar qualquer segmento de dados que possa ser útil.

Atribuir códigos a partes de dados é a maneira como as categorias começam a se formar. Depois da transcrição estar analisada e codificada, os códigos são agrupados de maneira a fazerem sentido quando juntos. O desafio é construir categorias que capturem algum padrão recorrente na análise dos dados.

Para este estudo, a análise de dados começou com a codificação aberta das transcrições. Ou seja, com a leitura da primeira transcrição, os códigos iniciais foram definidos. A cada leitura de novas transcrições, os códigos decorrentes de cada entrevista eram constantemente comparados aos códigos das entrevistas anteriores. A Tabela 4 ilustra um trecho da codificação inicial, merge e recodificação. No início deste processo, 282 códigos foram identificados. Com primeiro merge, esse número reduziu para 87. Com novos merges, o processo foi sendo refinado, resultando em 9 categorias, apresentadas na Tabela 3. Para o processo de codificação, foi utilizada a ferramenta Excel.

À medida que o processo de análise de dados progrediu, as relações entre as categorias puderam ser construídas. A Figura 1 ilustra a sequência de atividades realizadas desde a $1^{\mathrm{a}}$ codificação até a definição das relações.

Por fim, as categorias principais foram escolhidas de acordo com sua relevância dentro do contexto do fenômeno da internalização. A partir da definição das categorias 
centrais, foram definidas as proposições, o que possibilitou a interpretação das relações no fenômeno estudado, apresentada na Seção 5. A Tabela 3 ilustra as categorias centrais identificadas neste trabalho.

Tabela 4: Trecho da tabela de códigos iniciais e recodificação

\begin{tabular}{|c|c|c|}
\hline ID & CóDIGO & RECODIFICAÇÃO \\
\hline 1 & Ambiente de trabalho amigável & \multirow{5}{*}{ Ambiente de Trabalho } \\
\hline 2 & Ambiente de trabalho bem confortável & \\
\hline 3 & Ambiente descontraído & \\
\hline 4 & Ambiente não saudável & \\
\hline 5 & Ambiente visto como próprio & \\
\hline 6 & Crítica pessoal & \multirow{3}{*}{ Feedback } \\
\hline 7 & Crítica profissional & \\
\hline 8 & Críticas ajudam na evolução & \\
\hline 9 & Expectativa da empresa & \multirow{3}{*}{ Expectativas } \\
\hline 10 & Expectativa do membro mais novo em produzir de imediato & \\
\hline 11 & Expectativa em estar realizando um bom trabalho & \\
\hline 12 & Experiência & \multirow{4}{*}{ Experiência } \\
\hline 13 & Experiência passada do mais antigo para o mais novo & \\
\hline 14 & Experiência positiva com a chegada de um novo membro & \\
\hline 15 & Experiência tranquila em relação aos outros membros & \\
\hline
\end{tabular}

Sumarização (eliminação

de códigos que apontem

para o mesmo princípio)
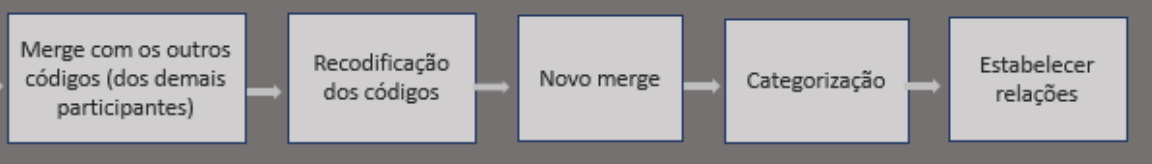

Figura 1: Sequência de atividades para a definição das relações

Tabela 3: Categorias identificadas

\begin{tabular}{|c|l|}
\hline ID & \multicolumn{1}{|c|}{ CATEGORIAS } \\
\hline 1 & Cultura da empresa \\
\hline 2 & Acolhimento/Integração do time \\
\hline 3 & Treinamentos \\
\hline 4 & Expectativa do trabalho \\
\hline 5 & Divisão da carga de trabalho \\
\hline 6 & Sentimento de perda (devido à saída de integrantes do time) \\
\hline 7 & Processos de desenvolvimento \\
\hline 8 & Processo de agregar valor com contribuição \\
\hline 9 & Abertura do diálogo \\
\hline
\end{tabular}

Neste ponto do estudo, os resultados foram consolidados. Foram utilizadas técnicas de verificação de membros para validar os achados, melhorando a precisão, credibilidade e validade interna das interpretações dos pesquisadores [Harper e Cole, 
2012; Kreftin, 1991]. Vale ressaltar que todas as relações identificadas foram apresentadas a 4 dos 7 respondentes e nenhum deles discordou dos resultados obtidos.

\section{Resultados}

Nesta seção serão detalhadas as categorias centrais do estudo, as quais foram obtidas das entrevistas com os 7 participantes, junto com a construção das relações entre essas categorias. A técnica de codificar, categorizar e sintetizar os dados levou à elaboração da narrativa central que explica os benefícios e limitações do processo de internalização de um novo membro em uma equipe de desenvolvimento de software.

No estudo, foram encontradas nove categorias (Tabela 3), sendo centrais as categorias "cultura da empresa" e o "acolhimento/integração do time". Com base nisto, foram estabelecidas as relações entre as categorias e estas são apresentadas na Figura 2 e descritas na sequência.

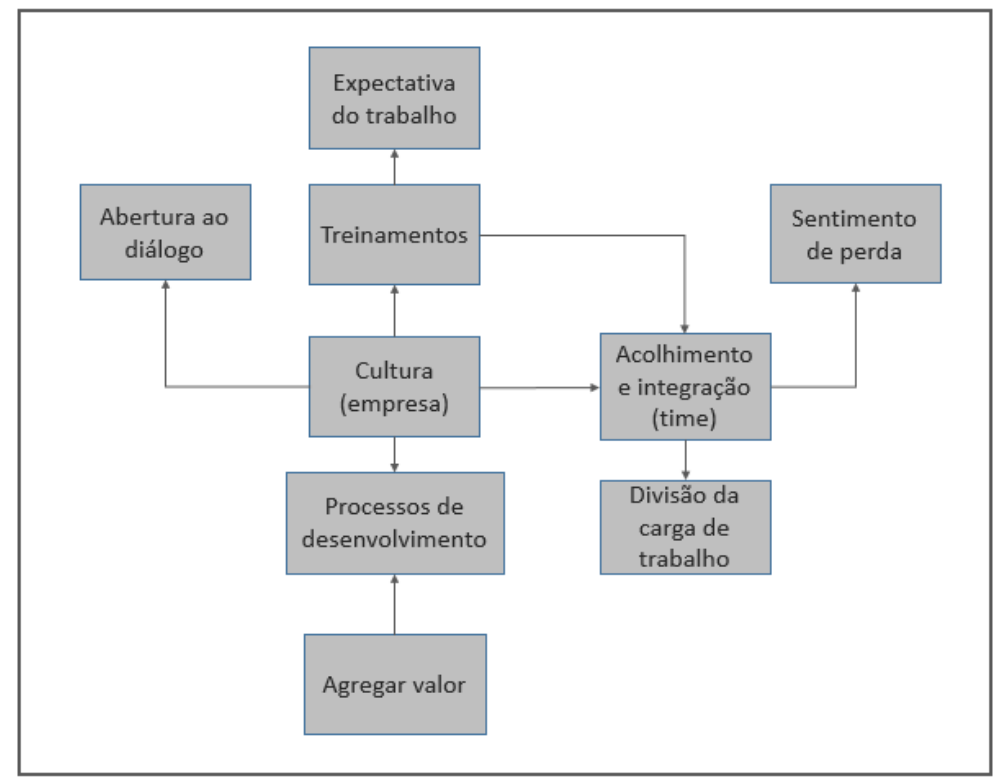

Figura 2: Relações entre as categorias

É importante destacar que todas as relações são de influência, onde as categorias causam ou sofrem a influência de alguma outra categoria. Percebe-se, por exemplo, que a categoria Expectativa do trabalho não exerce influência sobre nenhuma outra, porém, recebe influência da categoria Treinamentos.

As relações entre as categorias seguem exemplificadas na sequência, com trechos extraídos a partir das transcrições das entrevistas realizadas, identificadas pelos participantes (Tabela 2).

Relação 1 - A cultura da empresa influencia diretamente o acolhimento e integração do time.

"A entrada de um novo membro só tende a.. como é que eu posso dizer? Influenciar nessa cultura, afinal a cultura é feita pelo próprios (membros). É o próprio time". - P4.

"Todo mundo praticamente é uma família, tá todo mundo junto ali, disponível para ajudar um ao outro e tirar dúvidas, enfim. Eu acho que isso é o grande diferencial de trabalhar aqui". - P3. 
"Uma relação mais pessoal, então... ou quando isso vem mais para o ambiente de trabalho ou resolver algum problema a gente já tem mais facilidade de se comunicar com essas pessoas". $\mathrm{P} 2$.

O membro internalizado tem que se adequar a essa cultura para ser aceito. Se ele tem as características necessárias para essa forma de integração, ele permanece no grupo e é acolhido pelo mesmo. Caso contrário, apesar de o sentimento de perda dos demais, por todos "serem uma família", o membro termina sendo excluído naturalmente, e pelo fato de ele não estar agregando valor, essa saída termina sendo aceita pelos que ficam. Um ponto ressaltado por um deles foi que o conhecimento prévio de alguém do grupo facilita ainda mais o processo de integração e socialização do novo membro.

Relação 2 - A cultura da empresa influencia os treinamentos.

"Eu não tô conseguindo treinar ele da forma como deveria por conta de tempo mesmo, e.. acaba que o resto do time percebeu isso e tá ajudando muito ele ". - P5.

A cultura da empresa faz com que o novo integrante tenha tempo dedicado ao aprendizado sem cobranças iniciais por produtividade. Alguns chegam a comentar que isso causa estranheza. Além disso, eles recebem orientação sobre os processos, metodologia, etc. E só iniciam o processo de produção, de fato, após esse período de treinamento inicial para adaptação e acompanhamento. De todo jeito, nem todos possuem o mesmo grau de disponibilidade para essa ajuda/orientação inicial/capacitação mas, no geral, como há uma ajuda de todo o grupo, essa limitação é superada.

Relação 3 - Os treinamentos influenciam a expectativa do trabalho.

"Será que os sócios tão sabendo que eu tô em treinamento ainda?" - P6

"E ele fica doidinho, travado, aí ele ficou com muito medo e isso foi um ponto negativo". - P1

"Tô me sentindo meio improdutivo, porque eu acho que o pessoal tá esperando mais de mim. "P3.

Há uma preocupação e um sentimento de insegurança de quem chega para saber se está atendendo às expectativas. $\mathrm{O}$ novo integrante acredita que não está dando conta das demandas. Ele não leva em consideração que ainda está em fase de treinamento e que a cultura da empresa permite esse tempo inicial "improdutivo".

Há um entendimento geral de que os recém-chegados devem passar pelo período de integração sem a preocupação com a produtividade. $\mathrm{O}$ foco deve ser o entendimento da dinâmica do grupo e das relações de trabalho. Também existe o cuidado para que o novo integrante não se sinta cobrado por esse período de "improdutividade".

Relação 4 - Os treinamentos influenciam o acolhimento/integração.

"Confortável. Eh, bem acolhido pelas pessoas e confortável para trabalhar também, tecnicamente falando". - P6.

A medida que o recém-chegado conhece e está capacitado para realizar todo o processo técnico do trabalho, o processo de integração é facilitado, pois este se sente mais confiante e confortável junto a todo o grupo. Todo o período de treinamento facilita o processo de integração, de forma que todos passam a falar a mesma língua, possibilitando, ao recém-chegado, um sentimento de pertencimento de forma mais rápida. 
O grupo, por sua vez, acolhe o recém-chegado durante o processo de treinamento, uma vez que entende que este período é necessário para que o novo integrante se sinta parte do time.

Relação 5 - O acolhimento/integração influencia na divisão da carga de trabalho.

"Eu acho que dentro da equipe ele meio que desafogou o outro "Back-end", pois era muito atarefado e a gente tava num momento de transição de infraestrutura e aí ele meio que começou... eu senti que a chegada dele começou a diminuir esses gargalos". - $\mathrm{P} 4$.

"Eles sentiram que ia dar uma vazão maior em relação a alguns problemas, que os projetos de desenvolvimento que tem hoje em relação ao suporte técnico não tinham () de atenção e os clientes reclamavam bastante. Então o que eles pensavam é que ia ser mais rápido a solução dos problemas". - P2

"Com a minha chegada é exatamente isso que a gente quer, conseguir estabilizar esse problema com menos tempo e acredito que esteja sendo favorável". - P3

A internalização do novo membro foi vista por todos como uma possibilidade de melhor divisão da carga de trabalho e uma expectativa de que a carga de cada um poderia diminuir. Nas entrevistas realizadas ficou perceptível que as pessoas se sentiam motivadas, e até emocionadas com o acolhimento de todo o grupo durante a internalização, e isso gerava uma melhor adaptação, que pode ajudar a diminuir os gargalos, facilitando a redução da carga de trabalho para todos. Foi percebido, também, que a chegada de alguns ajudou a estabilizar e diminuir os problemas. a saída.

Relação 6 - O acolhimento/integração influencia no sentimento de perda devido

"Não é um sentimento agradável, lógico. São membros que a gente trabalhava e tinha uma relação de amizade, mas é um sentimento que olhando pelo lado de equipe, é um sentimento bom... Então quando o pessoal que não cumpre esse papel é desligado, é.. e a gente consegue suprir essas necessidades com pessoas que cumpram o papel com excelência, acaba que o peso que ficava pra você,é dividido em igual com todos os membros". - P1

"Eu sinto mais quando sai alguém, porque assim, gera um certo impacto já que você está trabalhando com aquela pessoa todos os dias. E querendo ou não alguma coisa já não está mais presente e o time querendo ou não tem que se reestruturar...". - P4

Há um impacto com a saída dos membros, no entanto, como a visão de grupo é mais forte, quando se percebe que a pessoa não está realizando seu papel e isso sobrecarrega o resto do grupo, a saída desse membro passa a ser vista como uma melhoria e o impacto é suavizado e dividido com todos os membros. O sentimento passa a ser positivo, pois fica claro que o membro está atrapalhando todo o time. Isso mostra claramente que há uma seleção natural para manter o grupo junto no mesmo objetivo.

Relação 7 - A cultura influencia o processo de desenvolvimento.

"A gente optou por fazer isso: usar o modelo rotativo do scrum master. Ou seja, em cada sprint, uma pessoa fica responsável... e geralmente quando um novo membro entra, eu peço para que o Scrum master introduza o novo membro nos métodos, nas práticas da gente, nos processos com relação tanto a sprint quanto a forma como a gente trabalha com um todo" - P1

"Sobre a entrada de um novo membro, é sempre bom, mas a princípio tem todo um tempo de adaptação. Então a gente precisou se habituar com isso inclusive, a gente começou a usar a política de programação em pares durante as duas primeiras semanas e de integrar a pessoa de 
fato num ambiente de desenvolvimento que a gente tem, de integrar a pessoa os produtos que a gente desenvolve. " - P5

$\mathrm{Na}$ empresa foi escolhida uma metodologia ágil de desenvolvimento e foi definido o modelo rotativo scrum master, para que todos possam experimentar papéis diferentes, como também a programação em pares, para que o acolhimento e a capacitação fiquem ainda mais fortes.

Relação 8 - O processo de agregar valor com contribuição influencia o processo de desenvolvimento.

"Cada um de nós sabe o papel de cada um dos integrantes do time. Isso facilita a nossa vida, porque a gente não precisa ficar quebrando a cabeça pra saber quem é o dono do problema. $O$ legal é que o dono sabe que o problema é dele e.... acaba chamando pra si a responsabilidade. Todos podem ajudar, mas o problema tem um dono. " - P2

$\mathrm{O}$ processo de agregar valor, melhorando qualidade das entregas, influencia o processo de desenvolvimento, pois reforça a necessidade de um método que torne todo o processo mais seguro e ágil para que as expectativas sejam atendidas.

Para que isso ocorra é importante a definição clara dos papéis e responsabilidades, que ficam bem definidas no processo de desenvolvimento escolhido. Todos os entrevistados, ao descrever a equipe, tinham a visão clara de qual seriam as contribuições do novo membro para a equipe, além de ter conhecimento sobre o papel $\mathrm{e}$ responsabilidade de cada membro.

Relação 9 - A cultura influencia a abertura do diálogo.

"A equipe sempre foi muito aberta em dialogar e discutir os pontos para que pudessem ser melhorados. Então ... a dificuldade foi só o primeiro entendimento, mas aí logo que se conversou, as dúvidas foram sanadas, propostas foram feitas e foram muito bem encaminhadas" - P4

"Tem uma coisa que valoriza o nosso trabalho em equipe que é tentar evitar hierarquizar as coisas. Eu gosto de deixar as coisas mais horizontais possíveis, mas também não deixar aquela bagunça. Eu acho que a forma como a gente trabalha, de a gente tenta comunicar os problemas e pensar junto como time na concepção da solução, eu acho que isso é crucial pra equipe. ”- P1

A cultura, baseada no processo de organização horizontalizada e com uma visão mais informal, influencia a abertura do diálogo do grupo, o processo de desenvolvimento escolhido, os treinamentos iniciais (para prover mais capacitação aos membros novos) e o acolhimento/integração (que facilita o processo de internalização).

Com base nas relações, percebe-se que a cultura da empresa é um fator determinante na internalização de novos membros. Quando o novo integrante se adequa à cultura, ocorre uma melhoria nas entregas, com maior valor agregado, sendo o processo de acolhimento positivo para todos. Por outro lado, percebe-se uma limitação: a de que os novos membros precisam se enquadrar nesse modelo, ou não serão aceitos. Quando um novo membro entra para o time, existe um forte acolhimento, mas se não há contribuição com a equipe, ele é substituído. A visão de grupo está sempre em primeiro lugar.

Com base nas relações apresentadas, a Tabela 5 aponta quais os benefícios e as limitações no processo de internalização. Como pontos positivos deste processo, percebese que o tempo hábil para o aprendizado é fundamental para o recém-chegado, o qual 
trará segurança após o período de integração. A clara distribuição dos papéis e de responsabilidades melhora a distribuição da carga de trabalho, tendo impacto na motivação do time. A diminuição dos problemas impacta na melhoria das entregas, proporcionando maior produtividade. Por fim, a sensação de acolhimento percebida pelo

\section{Tabela 5: Benefícios e Limitações}

\begin{tabular}{|l|}
\multicolumn{1}{|c|}{ BENEFÍCIOS } \\
\hline Acolhimento \\
\hline Clara distribuição dos papéis e responsabilidades \\
\hline Diminuição de problemas \\
\hline Maior integração da equipe \\
\hline Maior produtividade \\
\hline Melhor divisão da carga de trabalho \\
\hline Melhoria nas entregas \\
\hline Motivação \\
\hline Segurança (pós periodo de integração) \\
\hline Sentimento de pertencimento \\
\hline Tempo hábil para aprendizado \\
\hline LIMITAÇÕES \\
\hline Adequação a uma cultura pré-existente \\
\hline Insegurança (início da fase de treinamento) \\
\hline
\end{tabular}

recém-chegado influencia de maneira positiva na integração da equipe. Como pontos negativos, tem-se a insegurança sentida pelo recém-chegado no princípio deste processo, mas que pode ser minimizada pela fase de treinamentos, mencionada anteriormente. Um outro ponto negativo, e que merece atenção, é a de que o novo integrante deve se adequar a uma cultura pré-existente sob pena de não ser acolhido pelo grupo.

\section{Discussão}

Nesta seção serão discutidos os resultados encontrados, bem como os estudos relacionados, os quais estão indo na mesma direção dos achados deste trabalho.

Os resultados mostram que a cultura da empresa influencia diretamente no acolhimento dos novos integrantes, e consequentemente, na integração de todo o grupo. Mostra, também, que o novo membro, para ser aceito, tem que se adequar a essa cultura.

A cultura mais acolhedora permite que os novos membros possam ter um tempo inicial dedicado à aprendizagem, e define claramente o papel e responsabilidade de cada um, para garantir um melhor resultado de todos os trabalhos. Todo esse processo faz com que as pessoas se sintam mais confiantes e confortáveis com os seus desafios individuais, e isso tende a levar ao aumento da produtividade de todo o grupo ao longo do tempo. Outro ponto importante é que essa cultura de acolhimento também ajuda na divisão da carga de trabalho, o que ajuda a diminuir os gargalos existentes e a balancear melhor as atividades. Toda essa estrutura ajuda na motivação geral do grupo e no fortalecimento da visão da equipe.

Por outro lado, o processo se torna mais fechado uma vez que exige um perfil específico do novo integrante. Se esse indivíduo não se adapta, e se percebe que não está 
contribuindo como se esperava, ele é naturalmente excluído do grupo. Apesar do sentimento de perda que isso pode gerar, existe uma expectativa de ganho que o grupo vai ter, já que a contribuição dada pelo membro está fora do esperado.

Todo esse processo de mudança visa melhorar o desempenho de indivíduos no trabalho. Quem entra precisa se sentir acolhido e quem já conhece a cultura da empresa precisa compartilhar o padrão de comportamento e conhecimento técnico e do negócio com os novos membros. É preciso, também, respeitar o tempo de adaptação para que esse período inicial "improdutivo" possa ser compensado com uma maior integração que levará a melhores resultados futuros. Uma alerta é evitar a internalização simultânea de novos integrantes, uma vez que pode atrapalhar a atenção que precisa ser dada pelos membros já existentes ao novo recém-chegado.

Em relação aos trabalhos relacionados, percebe-se que este estudo está indo na mesma direção dos achados de Qureshi \& Fang (2011), Steinmacher et. al (2014) e Fagerholm e Guinea (2014), onde encontraram pontos positivos relacionados à socialização e à integração de recém-chegados em equipes de desenvolvimento de software. Para Qureshi \& Fang (2011), a socialização e a interação com os desenvolvedores principais tem um impacto significativo na progressão dos iniciantes. Essa troca pode resultar em acesso a informações úteis, apoio e patrocínio para iniciativas diversas. Já Steinmacher et. al (2014) apontam que a motivação e a atratividade influenciam a integração e a permanência dos membros nas equipes, e que a falta da motivação leva a desistências. No entanto, algumas forças opostas, os chamados "fatores impeditivos", podem dificultar o processo de adesão dos desenvolvedores. Essas forças compreendem fatores técnicos e não técnicos, incluindo curva de aprendizado, falta de apoio da comunidade, dificuldades em encontrar como começar etc. E Fagerholm e Guinea (2014) afirmam que o suporte dado aos desenvolvedores, como por exemplo a mentoria, influencia positivamente no processo de integração.

A descoberta empírica do atual estudo é amplamente consistente com o desenvolvimento teórico existente, onde percebe-se que iniciativas para facilitar a integração contribuem positivamente para a retenção de novos colaboradores. Porém, o trabalho atual expõe um fator que chama a atenção e que não foi abordado nos estudos mencionados: a cultura da empresa afeta fortemente o processo de internalização de novos membros, e isto deve ser melhor investigado.

\section{Ameaças à Validade}

Nesta seção serão discutidas as ameaças à validade dos resultados desta pesquisa através da perspectiva proposta por Travassos et al. (2002), o qual aborda o modelo conceitual de divisão por interesses: ameaças à validade de constructo, validade interna, validade externa e validade de conclusão.

Em relação à validade de construto, buscamos referenciar a literatura existente em torno da temática explorada. Além disso, analisamos a internalização a partir da identificação de seus benefícios e limitações em uma equipe de desenvolvimento de software. Foi utilizada uma abordagem qualitativa e os resultados produzidos com base na análise dos dados coletados por meio de entrevistas. Como forma a garantir a qualidade das entrevistas, uma entrevista teste (piloto) foi conduzida permitindo, assim, refinar o roteiro desenvolvido. Como forma de avaliar os resultados e mitigar o possível viés dos pesquisadores, foi aplicada a técnica de verificação de membros, onde os resultados 
produzidos foram apresentados para os participantes (entrevistados) da pesquisa, permitindo criar uma checagem de conformidade.

Quanto à validade interna, este estudo limitou-se a coletar dados de uma única empresa - uma startup. As relações foram estabelecidas a partir da identificação de influências entre as categorias e evidenciadas nos dados explorados. "Cultura da empresa" e "acolhimento/integração do time" apareceram de forma mais evidente, impactando nas demais categorias mencionadas. Para uma análise mais detalhada, cabe aumentar a amostra, além de uma investigação buscando definir as propriedades existentes sobre as categorias, uma vez que, o ambiente pode afetar a forma com que essas relações ocorrem.

No tocante à validade externa, o resultado produzido é um reflexo do ambiente explorado e, apesar de ser possível identificar características, estabelecer relações e identificar os benefícios e limitações da internalização em uma equipe de desenvolvimento, não é possível generalizar.

Por fim, como ameaças à validade de conclusão, tem-se que os resultados desta pesquisa refletem a investigação no processo de internalização de membros em uma equipe de desenvolvimento de software. As entrevistas capturaram o depoimento das principais partes envolvidas no processo, de um lado a equipe que acolhe o novo membro e do outro, o membro a ser internalizado. A análise dos dados permitiu estabelecer 9 relações existentes neste processo, especificadamente, na startup explorada.

\section{Conclusão}

Foram apresentados os resultados para o presente estudo, realizado com o objetivo de investigar os benefícios e limitações da internalização em equipes de desenvolvimento de software. Para tal, foi realizado um estudo qualitativo em uma startup onde a internalização foi observada recentemente. Os dados foram analisados utilizando técnicas de codificação qualitativa e os resultados foram verificados e validados com os participantes por meio da verificação de membros.

Os resultados indicam que existem pontos positivos e negativos no processo. Como positivos, tem-se o acolhimento do grupo ao recém-chegado, a clara distribuição dos papéis e responsabilidades dos integrantes do time, a diminuição de problemas, uma maior integração da equipe, maior produtividade, melhor divisão da carga de trabalho, melhoria nas entregas, maior motivação, maior segurança, sentimento de pertencimento pelo recém-chegado e tempo hábil para o aprendizado. Como pontos negativos, percebese que o indivíduo deve se adequar a uma cultura pré-existente, além da insegurança sentida no início da integração.

Com base nos resultados, a internalização de novos membros, se feita de forma a garantir uma maior homogeneidade do grupo, gera uma maior sinergia, que ajuda fortemente no objetivo dos resultados organizacionais. Porém, é necessário ficar atento a este processo para não criar um grupo tão fechado que dificulte a aceitação de novos membros, já que o processo de mudança sempre vai ocorrer.

Como trabalhos futuros, é possível novos estudos que possam fazer uma expansão da amostra de dados utilizada, com o objetivo de produzir novas descobertas em torno das relações estabelecidas e os benefícios e limitações identificadas. Dado o ambiente propício ao processo de internalização, é recomendável utilizar startups como o público

iSys: Revista Brasileira de Sistemas de Informação (iSys: Brazilian Journal of Information Systems) 
alvo em novas pesquisas. Outros cenários também podem ser explorados, buscando verificar as possíveis semelhanças e diferenças com os aspectos abordados neste estudo. Ainda, pesquisas futuras podem explorar os mecanismos por trás do processo de internalização de forma mais detalhada, e de que forma a cultura pode influenciar no processo de internalização, uma vez que aparece como fator determinante nesse processo. Investigar qual o impacto dessa variável dentro desse contexto, é recomendável.

\section{Agradecimentos}

Agradecemos à CAPES pelo apoio financeiro ao desenvolvimento de pesquisas de pósgraduação, cedido por meio de bolsa de estudo para Joelson Isidro da Silva Araújo.

\section{Referências}

Bauer, T. N., Bodner, T., Erdogan, B., Truxillo, D. M., \& Tucker, J. S. (2007). Newcomer adjustment during organizational socialization: a meta-analytic review of antecedents, outcomes, and methods. Journal of applied psychology, 92(3), 707.

Berger, P. L., \& Luckmann, T. (1991). The social construction of reality: A treatise in the sociology of knowledge (No. 10). Penguin Uk.

Bowditch, J. L.; Buono, A. F. Fundamentos de Comportamento Organizacional. Tradução Luiz Henrique Baptista Machado; revisão técnica Antônio Eugênio Valverde Mariani Passos. Rio de Janeiro: LTC, 2006.

Cameron, K. S., \& Quinn, R. E. (2011). Diagnosing and changing organizational culture: Based on the competing values framework. John Wiley \& Sons.

Campbell, D., Edgar, D., \& Stonehouse, G. (2011). Business strategy: an introduction. Macmillan International Higher Education.

Cannon-Bowers, J. A., \& Bowers, C. (2011). Team development and functioning.

Capretz, L. F., \& Ahmed, F. (2010). Making sense of software development and personality types. IT professional, 12(1), 6-13.

Capretz, L. F., Ahmed, F., \& da Silva, F. Q. B. (2017). Soft sides of software. arXiv preprint arXiv:1711.07876.

Chow, T., \& Cao, D. B. (2008). A survey study of critical success factors in agile software projects. Journal of systems and software, 81(6), 961-971.

Cohen, D., \& Crabtree, B. (2006). Qualitative Research Guidelines Project. Disponível em http://www.qualres.org.

Cunha, A. (2014). A arte da guerra na liderança (2ªd). Lisboa: TopBooks.

Damian, D.; Zowghi, D. An insight into the interplay between culture, conflict and distance in globally distributed requirements negotiations. In: Hawaii International Conference On System Sciences, 36., Hawaii, 2003.

DeOrtentiis, P. S., Summers, J. K., Ammeter, A. P., Douglas, C., \& Ferris, G. R. (2013). Cohesion and satisfaction as mediators of the team trust-team effectiveness relationship. Career Development International.

Doyle, S. (2007). Member checking with older women: A framework for negotiating 
meaning. Health care for women international, 28(10), 888-908.

Faegri, T. E. (2009, August). Improving general knowledge in agile software organizations: experiences with job rotation in customer support. In 2009 Agile Conference (pp. 49-56). IEEE.

Fægri, T. E., Dybå, T., \& Dingsøyr, T. (2010). Introducing knowledge redundancy practice in software development: Experiences with job rotation in support work. Information and Software Technology, 52(10), 1118-1132.

Fagerholm, F., Guinea, A. S., Borenstein, J., \& Münch, J. (2014). Onboarding in open source projects. IEEE Software, 31(6), 54-61.

Faraj, S., \& Sproull, L. (2000). Coordinating expertise in software development teams. Management science, 46(12), 1554-1568.

Farshchi, M., Jusoh, Y. Y., \& Murad, A. A. M. (2012). Impact of personnel factors on the recovery of delayed software projects: A system dynamics approach. Computer Science and Information Systems, 9(2), 627-652.

Gil, A. C. (2002). Como elaborar projetos de pesquisa (Vol. 4, p. 175). São Paulo: Atlas.

Grant, R. M. (1996). Prospering in dynamically-competitive environments: Organizational capability as knowledge integration. Organization science, 7(4), 375387.

Harper, M., \& Cole, P. (2012). Member checking: Can benefits be gained similar to group therapy. The qualitative report, 17(2), 510-517.

Hermanto, S., Kaburuan, E. R., \& Legowo, N. (2018, October). Gamified SCRUM Design in Software Development Projects. In 2018 International Conference on Orange Technologies (ICOT) (pp. 1-8). IEEE.

Hoopes, D. G., \& Postrel, S. (1999). Shared knowledge,"glitches," and product development performance. Strategic management journal, 20(9), 837-865.

Kobitzsch, W.; Rombach, D.; Feldmann, R. L. Outsourcing in India. IEEE Software, v.18, n.2, p.78-86, March/April 2001.

Kozlowski, S. W., \& Ilgen, D. R. (2006). Enhancing the effectiveness of work groups and teams. Psychological science in the public interest, 7(3), 77-124.

Krefting, L. (1991). Rigor in qualitative research: The assessment of trustworthiness. American journal of occupational therapy, 45(3), 214-222.

Lindsjørn, Y., Sjøberg, D. I., Dingsøyr, T., Bergersen, G. R., \& Dybå, T. (2016). Teamwork quality and project success in software development: A survey of agile development teams. Journal of Systems and Software, 122, 274-286.

Louis, M. R. (1980). Surprise and sense making: What newcomers experience in entering unfamiliar organizational settings. Administrative science quarterly, 226-251.

MacGregor, E., Hsieh, Y., \& Kruchten, P. (2005). Cultural patterns in software process mishaps: incidents in global projects. ACM SIGSOFT Software Engineering Notes, 30(4), 1-5.

Manzini, E. J. (1990). A entrevista na pesquisa social. Didática, 26, 149-158. 
Maruping, L. M., Zhang, X., \& Venkatesh, V. (2009). Role of collective ownership and coding standards in coordinating expertise in software project teams. European Journal of Information Systems, 18(4), 355-371.

Merli, A. M. (2008). Gestão por competências. Rio de Janeiro: Qualitymark.

Merriam, S. B., \& Tisdell, E. J. (2015). Qualitative research: A guide to design and implementation. John Wiley \& Sons.

Merriam, S. B. (2009). Qualitative research: A guide to design and implementation. Journal of Chemical Information and Modeling.

Miranda, R. (2011). Uma Revisão Sistemática Sobre Equipes de Desenvolvimento de Software: Tipologia, Características e Critérios de Formação. Centro de Informática (CIn), Universidade Federal de Pernambuco.

Moe, N. B., \& Dingsøyr, T. (2008, June). Scrum and team effectiveness: Theory and practice. In International conference on agile processes and extreme programming in software engineering (pp. 11-20). Springer, Berlin, Heidelberg.

Moe, N. B., Dingsøyr, T., \& Dybå, T. (2010). A teamwork model for understanding an agile team: A case study of a Scrum project. Information and Software Technology, 52(5), 480-491.

Moe, N. B., \& Šmite, D. (2008). Understanding a lack of trust in Global Software Teams: a multiple-case study. Software Process: Improvement and Practice, 13(3), 217-231.

Mockus, A.; Herbsleb, J. D. Challenges of Global Software Development. In: International Software Metrics Symposium, 7., London, 2001.

Moser, P., Araújo, J., Oliveira, E., Ferreira, H., \& Pereira, C. (2019, July). Internalização de novos membros em equipes de desenvolvimento de software: benefícios e limitações. In Anais do IV Workshop sobre Aspectos Sociais, Humanos e Econômicos de Software (pp. 61-70). SBC.

Mourmant, G., \& Gallivan, M. (2007, April). How personality type influences decision paths in the unfolding model of voluntary job turnover: an application to IS professionals. In Proceedings of the 2007 ACM SIGMIS CPR conference on Computer personnel research: The global information technology workforce (pp. 134143).

Nonaka, I., \& Takeuchi, H. (1995). The knowledge-creating company: How Japanese companies create the dynamics of innovation. Oxford university press.

Oliveira, S., L. (2011). Sociologia das organizações: uma análise do homem e das empresas no ambiente competitivo. São Paulo: Pioneira.

Oliveira, R., \& França, C. (2019). Agile Practices and Motivation: A quantitative study with Brazilian software developers. In Proceedings of the Evaluation and Assessment on Software Engineering (pp. 365-368).

Ollo-Lopez, A., Bayo-Moriones, A., \& Larraza-Kintana, M. (2010). The relationship between new work practices and employee effort. Journal of industrial relations, 52(2), 219-235. 
Pikkarainen, M., Haikara, J., Salo, O., Abrahamsson, P., \& Still, J. (2008). The impact of agile practices on communication in software development. Empirical Software Engineering, 13(3), 303-337.

Qureshi, I., \& Fang, Y. (2011). Socialization in open source software projects: A growth mixture modeling approach. Organizational Research Methods, 14(1), 208-238.

Quinn, R. E. (2003). Competências gerenciais: princípios e aplicações. Elsevier.

Rea, L. M. (2000). Metodologia de Pesquisa-do planejamento a execução. Cengage Learning Editores.

Robbins, S. P. Comportamento organizacional.11.ed. SãoPaulo: Pearson Prentice Hall,2005.

Santos, R. E., Da Silva, F. Q., de Magalhães, C. V., \& Monteiro, C. V. (2016, May). Building a theory of job rotation in software engineering from an instrumental case study. In Proceedings of the 38th International Conference on Software Engineering (pp. 971-981).

Santos, R. E., da Silva, F. Q., \& de Magalhães, C. V. (2016, June). Benefits and limitations of job rotation in software organizations: a systematic literature review. In Proceedings of the 20th International Conference on Evaluation and Assessment in Software Engineering (pp. 1-12).

Santos, R. E. D. S. (2015). The Influence of Job Rotation on Motivation and Satisfaction of Software Engineers (Master's thesis, Universidade Federal de Pernambuco).

Silva, R. C. D. C. (2017). Um estudo sobre a influência de fatores humanos e culturais em projetos de desenvolvimento de software ágeis (Master's thesis, Universidade Federal de Pernambuco).

Silva, A. H., \& Fossá, M. I. T. (2015). O Processo de Socialização Organizacional como Estratégia de Integração Indivíduo e Organização. Administração de Empresas em Revista, 14(15), 186-203.

Steinmacher, I., Gerosa, M. A., \& Redmiles, D. (2014, February). Attracting, onboarding, and retaining newcomer developers in open source software projects. In Workshop on Global Software Development in a CSCW Perspective.

Schein, E. H. (1984). Coming to a new awareness of organizational culture. Sloan management review, 25(2), 3-16.

Scott, J., F. (1971). Internalization of norms: A sociological theory of moral commitment. Oxford, England: Prentice-Hall.

Sharp, H., \& Robinson, H. (2010). Three 'C's of agile practice: collaboration, coordination and communication. In Agile software development (pp. 61-85). Springer, Berlin, Heidelberg.

Tessem, B., \& Maurer, F. (2007, June). Job satisfaction and motivation in a large agile team. In International Conference on Extreme Programming and Agile Processes in Software Engineering (pp. 54-61). Springer, Berlin, Heidelberg.

Travassos, G. H., Gurov, D., \& Amaral, E. A. G. G. (2002). Introdução à engenharia de software experimental. 
Trivinos, A. N. S. Introdução à pesquisa em ciências sociais: a pesquisa qualitativa em Educação. São Paulo: Atlas; 1987.

Tyler, T. R. (1997). Why people cooperate with organizations. Research in Organization Behavior, 21, 201-246.

Viana, D., Conte, T., Vilela, D., de Souza, C. R., Santos, G., \& Prikladnicki, R. (2012). The influence of human aspects on software process improvement: Qualitative research findings and comparison to previous studies.

Whitehead, J. (2007, May). Collaboration in software engineering: A roadmap. In Future of Software Engineering (FOSE'07) (pp. 214-225). IEEE.

Wood, S. (1999). Human resource management and performance. International journal of management reviews, 1(4), 367-413. 


\section{Apêndice A}

\section{Termo de Consentimento}

O objetivo desta pesquisa é entender aspec tos relacionados à dinâmica das equipes de desenvolvimento de software.

Todas as informações fornecidas por você nesta entrevista serão confidenciais, apenas a pesquisadora terá acesso a essas informações. Em particular, nenhuma pessoa direta ou indiretamente ligada a sua empresa terá acesso às informações fornecidas nesta entrevista e em nenhuma outra fase de coleta de dados da pesquisa. Os pesquisadores empregarão todos os meios possíveis para evitar que informações individuais possam ser associadas diretamente aos respondentes.

Sua participação nesta pesquisa é voluntária e você pode decidir não participar ou se retirar da pesquisa a qualquer momento. Caso você decida não participar, não receberá nenhuma sanção ou penalidade. Caso você concorde em participar desta pesquisa, por favor, preencha os campos abaixo. As informações a seguir serão utilizadas caso a pesquisadora precise entrar em contato com você no futuro para esclarecimentos sobre a entrevista.

Nome completo:

E-mail:

Data:

Assinatura: 


\section{Roteiro da Entrevista:}

- Apresentação do pesquisador e cumprimentos

- Agradecimento ao participante

- Apresentação e assinatura do termo de consentimento

Para auxiliar no processo de análise dos dados será utilizado um gravador para não perder nenhum detalhe importante mencionado durante a entrevista. Você permite que a entrevista seja gravada?

Sobre a entrevista:

- As perguntas que farei nessa entrevista exigirão que você faça reflexões aprofundadas. Quanto mais detalhada for a sua resposta, mais informações teremos para analisar. Por favor, não tenha pressa ao responder, todos os detalhes nos interessam.

- Quanto tempo disponível você tem para conversarmos hoje? Caso a gente não consiga concluir todas as perguntas do roteiro podemos marcar um $2^{\circ}$ encontro num outro dia e horário mais conveniente para você?

\section{Perguntas:}

As perguntas que irei fazer se referem às suas experiências e sentimentos em relação ao trabalho na sua equipe de desenvolvimento de software aqui na EMPRESA. Vamos começar com perguntas gerais sobre a sua equipe e como é trabalhar nela, pode ser?

1. Por favor, me descreva no maior nível de detalhes possível a equipe na qual você trabalha atualmente.

Probe: Quantos membros? Quem são os membros? Estrutura e papéis?

2. A sua equipe tem um "nome"? Quando alguém quer se referir a sua equipe, como isso é feito?

(Observação para o entrevistador: o objetivo com esta pergunta é saber se existe uma identidade da equipe ou se ela é associada ao projeto que está sendo desenvolvido).

3. Há quanto tempo vocês trabalham juntos?

Probe: Qual era a formação inicial da equipe? Você está na equipe desde o início da sua formação? Quando você se integrou na equipe?

(Observação para o entrevistador: a resposta para esta pergunta vai se conectar com a pergunta 7. Não pule as próximas perguntas. Continue na pergunta 4).

4. Durante esse tempo de $X$ anos que vocês estão trabalhando juntos, em quais projetos vocês trabalharam?

5. Caso eu fosse um@nov@ funcionári@, e hoje fosse o meu primeiro dia de trabalho nesta equipe, como você descreveria como é trabalhar nesta equipe pra mim? 
Probe: Como esta equipe me receberia?

6. De forma geral, tem mais alguma coisa relacionada ao trabalho da sua equipe que você acha importante ressaltar?

Obrigado. Consigo agora ter uma boa visão geral da sua equipe. As próximas perguntas são relacionadas a mudanças nos membros da equipe.

7.A. Você me disse que está na equipe desde o início da sua formação, certo?

Nesse período, houve mudanças na equipe (entrada e saída) de membros?

Probe: você sabe dizer qual foi o motivo da mudança?

8.A. Como você se sente quando existe uma mudança?

Probe: Em particular, como você se sente com a chegada de um novo membro na equipe?

9.A. Na sua opinião, como a equipe se comporta com a chegada de um novo membro?

10.A. Por favor, me descreva em detalhes como se deu a última chegada de um membro novo na equipe.

Probe: Quem foi esse membro? Qual função/papel na equipe? Qual a experiência anterior do novo membro? Foi uma seleção interna ou externa?

11.A. Destaque os principais pontos positivos que resultaram da chegada deste novo membro?

Probe: Como a equipe contribuiu para estes resultados positivos?

12.A. Agora, destaque os principais pontos negativos da chegada desse novo membro?

Probe: Como a equipe contribuiu para estes resultados negativos? Como estes resultados negativos foram tratados pela equipe?

Probe: no caso de o entrevistado falar sobre problemas com a saída de outro membro, aceita a resposta e pergunta de novo sobre a entrada.

7.B. Você me disse que chegou nessa equipe quando ela já estava trabalhando há $\mathrm{X}$ anos, certo? Pois bem, você pode me descrever em detalhes como foi a sua entrada na equipe?

Probe: Você já era da empresa? Foi contrato para trabalhar na equipe? Já conhecia os membros da equipe? Já tinham trabalhado junto em outras equipes?

8.B. Como você se sentiu nos primeiros dias de trabalho nessa equipe?

9.B. Na sua opinião, como você acha que os outros membros da equipe se sentiram com a sua chegada, nos primeiros dias?

10.B. Destaque os principais pontos positivos que resultaram da sua chegada na equipe? Probe: Como a equipe contribuiu para estes resultados positivos?

11.B. Agora, destaque os principais problemas enfrentados na sua chegada?

Probe: Como estes problemas foram tratados pela equipe? 
(Observação para o entrevistador: caso este membro não seja o mais novo membro da equipe, volte para a pergunta 10.A. e depois de terminar 12.A passe para 13).

13. Sobre o que conversamos em relação à chegada de novos membros na equipe, existe alguma coisa que você gostaria de acrescentar?

14. Em geral, sobre sua experiência em trabalhar em equipe, existe mais alguma coisa que você queira compartilhar conosco?

Obrigado. Suas contribuições foram muito importantes. 